\title{
Qualidade e compostos fenólicos em sementes de mamão alterados pela colheita e maturação dos frutos
}

\author{
Quality and phenolic compounds in papaya seeds changed by harvest and maturity of fruits
}

\author{
Maristela Aparecida Dias ${ }^{\mathrm{I}}$ Denise Cunha Fernandes dos Santos Dias ${ }^{\text {II }}$ \\ Eduardo Euclydes de Lima e Borges ${ }^{\text {II }}$ Luiz Antônio dos Santos Dias ${ }^{\text {II }}$
}

\section{RESUMO}

A presença de compostos fenólicos nas estruturas das sementes de mamão pode interferir no processo de germinação, de forma que o objetivo no estudo foi avaliar o efeito da época de colheita e da maturação dos frutos sobre a ocorrência de compostos fenólicos e qualidade de sementes de mamão. Os frutos foram colhidos em abril e outubro de 2010 e as sementes extraídas nos estádios 1, 3, 5 e final da maturação, correspondendo a cerca de 15, 50, 75 e 100\% da casca amarela, respectivamente. Em cada estádio, sementes com e sem sarcotesta foram avaliadas quanto à porcentagem de germinação, primeira contagem, envelhecimento acelerado, sementes dormentes e conteúdo de fenóis nas sementes pelo método de Folin-Ciocalteau em delineamento inteiramente ao acaso. As sementes com maior porcentagem de germinação e nível de vigor foram as dos frutos no estádio 5 e final da maturação; a sarcotesta contém maior concentração de fenóis em relação às demais estruturas.

Palavras-chave: Carica papaya L., armazenamento de frutos, compostos inibidores, dormência.

\section{ABSTRACT}

The presence of phenolic compounds in the papaya seed structures can interfere with the germination process, so the objective in the study was to evaluate the effect of the harvest season and maturation stage of the fruit changing the inhibitory compounds presence and physiological quality in papaya seeds. Fruits of papaya were collected in April and October, 2010, and seeds extracted of the stage 1, 3, 5 and final of maturation, corresponding to about 15, 50, 75 and $100 \%$ of yellow peel respectively. Seeds with and without sarcotesta were evaluated by test of germination, first counting, accelerated aging, percentage of dormant seeds, and content of phenols in seed by method of Folin-Ciocalteau in completely randomized design The Seeds with higher germination and vigor level were the fruits at stage 5 and final of maturation. The sarcotesta contains a higher concentration of phenols in relation to other structures.

Key words: Carica papaya L., storage of fruits, inhibitors compounds, dormancy.

\section{INTRODUÇÃO}

A produção mundial de mamão (Carica papaya L.) representa $10 \%$ da produção de frutas, destacando-se como maiores produtores a Índia, Brasil, Indonésia e Nigéria (FAO, 2009). O mamoeiro é uma cultura na qual a intensa ocorrência de viroses faz com que seja necessária, a cada dois ou três anos, a renovação dos pomares; além disso, o uso da sexagem para obtenção de pomares com maior número de plantas hermafroditas e a ocorrência de dormência nas sementes são fatores que contribuem para uma elevada demanda por sementes (ALMEIDA, 2007).

Nesse aspecto, a qualidade fisiológica das sementes reveste-se de grande importância, estando diretamente relacionada à obtenção de pomares uniformes. Assim, estudos referentes à qualidade fisiológica de sementes de mamão precisam ser implementados, uma vez que sua germinação é lenta e irregular (MARTINS et al., 2005; TOKUHISA et al., 2007a) e os mecanismos responsáveis por tal comportamento ainda estão pouco esclarecidos.

As sementes de mamão são revestidas por um envelope mucilaginoso, denominado sarcotesta,

Instituto Capixaba de Pesquisa (Incaper), Assistência Técnica e extensão Rural, Vitória, ES, Brasil. E-mail: diasmunizf@gmail.com.br. Autor para correspondência.

"Universidade Federal de Viçosa (UFV), Viçosa, MG, Brasil. 
cuja presença pode reduzir o poder germinativo, pois contém compostos fenólicos que podem atuar como inibidores da germinação (TOKUHISA et al., 2007a). A presença da sarcotesta reduziu a germinação das sementes e o desenvolvimento das plântulas oriundas de sementes de Jaracatia spinosa (Aubli) A. DC., espécie pertencente à família Caricaceae, sendo que esta redução estaria associada à presença de inibidores (FREITAS et al., 2011). Alguns trabalhos têm demonstrado o efeito de compostos fenólicos na inibição da germinação de sementes de mamão (CHOW \& LIN, 1991, TOKUHISA et al., 2007b).

Outros fatores podem também interferir na germinação das sementes de mamão, como a época de colheita e o estádio de maturação dos frutos, fato comprovado por TOKUHISA et al. (2008), quando verificaram que a intensidade da dormência das sementes variou conforme a época de colheita. Quanto ao estádio de maturação dos frutos, LOPES et al. (2009), ao avaliarem sementes de mamão obtidas do fruto no estádio "de vez" e maduro, não obtiveram germinação em sementes recém-colhidas, independente do estádio de maturação. Assim, o trabalho foi desenvolvido com o objetivo de avaliar o efeito de época de colheita e estádio de maturação do fruto sobre a qualidade fisiológica e presença de compostos inibidores nas estruturas de sementes de mamão.

\section{MATERIAL E MÉTODOS}

Os frutos de mamão Formosa 'Tainung 01' foram colhidos em abril e outubro de 2010, no município de Pinheiros-ES, quando estavam com até $15 \%$ da superfície da casca amarela (estádio 1) (AROUCHA et al., 2005). A temperatura média registrada na região durante o desenvolvimento dos frutos colhidos em abril (dezembro de 2009 a março de 2010) foi de $27^{\circ} \mathrm{C}$, atingindo máxima de $35^{\circ} \mathrm{C}$ e mínima de $20,5^{\circ} \mathrm{C}$. Para os frutos colhidos em outubro (formados entre junho a setembro de 2010), a temperatura média do período foi de $21^{\circ} \mathrm{C}$, máxima de $29^{\circ} \mathrm{C}$ e mínima de $15^{\circ} \mathrm{C}$ (INCAPER, 2011).

Os frutos foram levados ao Laboratório de Sementes da Universidade Federal de Viçosa, onde se realizou a extração das sementes no estádio 1 , sendo os demais armazenados em ambiente de laboratório (cerca de $25^{\circ} \mathrm{C}$ e $70 \%$ UR). As sementes foram extraídas quando os frutos atingiram os estádios de maturação estabelecidos por AROUCHA et al. (2005): estádios 3 e 5 , correspondendo a até 50 e $75 \%$ da superfície externa da casca amarela, respectivamente, e estádio final, quando estavam completamente amarelos (100\% da casca amarela). Após a extração, uma parte das sementes foi mantida com sarcotesta e a outra friccionada manualmente sobre peneira até a sua completa remoção e, em seguida, foram postas para secar sobre papel, em ambiente de laboratório, até atingirem grau de umidade aproximado de $10 \%$, para serem avaliadas por meio dos testes descritos a seguir.

Teste de germinação - quatro repetições de 50 sementes foram dispostas entre folhas papel especial para germinação umedecidas com água destilada em volume equivalente a 2,5 vezes o peso do papel seco. Os rolos foram confeccionados e mantidos em estufa tipo Biological Oxygen Demand (B.O.D.), regulada a temperatura de $20-30^{\circ} \mathrm{C}(16 / 8 \mathrm{~h})$ e fotoperíodo de oito horas (BRASIL, 2009). Embora as Regras para Análise de Sementes (BRASIL, 2009) recomendem que a primeira contagem seja realizada aos sete dias, não foi constatada germinação nesta data, sendo esta avaliação realizada aos 15 e a avaliação final aos 30 dias.

Para determinação das sementes dormentes após o teste, a sarcotesta foi retirada e o endosperma seccionado longitudinalmente para exposição do embrião, sendo colocados em solução de tetrazólio a $0,05 \%$ por 12 horas, no escuro, a $35^{\circ} \mathrm{C}$, conforme testes preliminares. Em seguida, as sementes foram lavadas em água corrente e individualmente observadas em lupa, sendo aquelas sementes que apresentavam embriões de coloração róseo brilhante e consistência firme consideradas viáveis e dormentes.

Envelhecimento acelerado (EA) - duas repetições de 100 sementes de cada tratamento foram distribuídas em camada única sobre tela acoplada a caixas de acrílico transparentes contendo, ao fundo, $40 \mathrm{~mL}$ de água. As caixas foram fechadas e mantidas em câmara de germinação do tipo B.O.D. a $41^{\circ} \mathrm{C}$ por 48 horas e, em seguida, foi realizado o teste de germinação (BRASIL, 2009).

Determinação de fenóis totais - foram separadas a sarcotesta, esclerotesta e a parte interna (endosperma + embrião) das sementes, as quais foram secas em estufa de circulação de ar a $35^{\circ} \mathrm{C}$ por 24 horas, posteriormente trituradas e três gramas do material depositados em um recipiente, adicionando-se $30 \mathrm{~mL}$ de etanol a $80 \%$. O conteúdo foi levado ao extrator com condensador e mantido em ebulição durante 90 minutos, cujo extrato foi filtrado a vácuo, seguindo-se a evaporação do etanol em rotaevaporador a $40^{\circ} \mathrm{C}$.

Em seguida, as amostras foram centrifugadas durante 10 minutos a $4^{\circ} \mathrm{C}$ a $10.000 \mathrm{rpm}$, sendo o sobrenadante transferido para frascos, nos 
quais foi injetado gás nitrogênio, vedados e congelados a $-30^{\circ} \mathrm{C}$ (SWAINT \& HILLIS, 1959) e a curva padrão com ácido fenílico foi construída $(\mathrm{y}=0,001 \mathrm{x}+0,127)$. Para quantificação dos fenóis, $25 \mu \mathrm{L}$ da amostra foi adicionada em água destilada, completando-se o volume para $3,5 \mathrm{~mL}$, em seguida, $0,25 \mathrm{~mL}$ do reagente Folin-Ciocalteau foi adicionado e os tubos agitados. Na sequência, adicionou-se $0,5 \mathrm{~mL}$ de solução saturada de carbonato de sódio agitando-se novamente os tubos. Por fim, o volume foi elevado para $5 \mathrm{~mL}$ com água destilada. Após uma hora no escuro, leu-se a absorbância a 730nm em espectrofotômetro UVVisível modelo C618-0437. Os resultados foram expressos em $\mu \mathrm{g}$ de fenol $\mathrm{g}^{-1} \mathrm{MS}^{-1}$.

$\mathrm{O}$ experimento foi conduzido em delineamento inteiramente casualizado (DIC). Os dados obtidos nos testes de germinação e de envelhecimento acelerado analisados em esquema fatorial $2 \times 4$ (épocas de colheita e estádios de maturação); 2x2 (épocas de colheita e presença ou ausência de sarcotesta); e 2x2 (estádios de maturação e épocas de colheita) em quatro repetições.

Para compostos fenólicos, foram utilizadas três repetições analisadas em triplicata e os tratamentos dispostos em esquema fatorial $2 \times 3$ (épocas de colheita e estruturas da semente - sarcotesta, esclerotesta e endosperma + embrião). Os dados foram submetidos à análise de variância pelo teste $\mathrm{F}(\mathrm{P} \leq 0,05 \mathrm{e} \leq 0,01)$ e as médias comparadas pelo teste de Tukey $(\mathrm{P} \leq 0,05)$. Os valores percentuais foram previamente submetidos à transformação angular e o processamento dos dados foi realizado com o software SAS (DELWICHE \& SLAUGHTER, 2003).

\section{RESULTADOS E DISCUSSÃO}

O período de armazenamento pós-colheita dos frutos permitiu o seu amadurecimento e promoveu o aumento na germinação das sementes (Tabela 1), de forma que, em frutos nos estádios 5 e final da maturação, a remoção da sarcotesta contribuiu para uma maior porcentagem. Os resultados referentes ao efeito do armazenamento pós-colheita, concordam com o que foi verificado por AROUCHA et al. (2005), em sementes de mamão obtidas de frutos em diferentes estádios de maturação. Resultados semelhantes também foram observados por DIAS et al. (2006), em sementes de tomate.

Pelo teste de tetrazólio, constatou-se que as sementes não germinadas não estavam mortas e sim dormentes. Assim, a proporção de sementes dormentes foi maior em frutos no estádio 1 de maturação, ocorrendo redução desta proporção com o amadurecimento dos frutos (Tabela 1). Comparando sementes com e sem sarcotesta, verificou-se maior ocorrência de dormência naquelas sem tal estrutura, obtidas de frutos nos estádios de maturação 1 e 3 .

Nestes estádios, a remoção da sarcotesta pode ter promovido, simultaneamente, a perda de compostos que seriam utilizados pelas sementes nas fases posteriores para estruturação das paredes celulares, ou, ainda, ter interferido, removendo substâncias promotoras da germinação presentes naquela estrutura, o que explica o efeito benéfico do armazenamento dos frutos sobre a qualidade das sementes, conforme verificado também por MARTINS et al. (2006). As alterações que ocorrem nas sementes durante este processo, no entanto, ainda precisam de maiores estudos, sendo escassas as informações na literatura, pois independente do estádio de maturação avaliado, sementes sem sarcotesta submetidas ao envelhecimento acelerado foram as de maior vigor (Tabela 1).

Pelos resultados referentes à interação entre épocas de colheita e presença/ausência de sarcotesta nas sementes (Tabela 2), observa-se que, em sementes de frutos colhidos em abril, não houve efeito da remoção sobre a germinação. No entanto, para os frutos colhidos em outubro, a remoção da estrutura teve efeito significativo sobre o processo. Tanto em presença como em ausência de sarcotesta, para sementes de frutos colhidos em abril, obtevese percentual de germinação superior ao daquelas extraídas de frutos colhidos em outubro.

Esse comportamento indica o efeito das variações climáticas ocorridas no período de formação das sementes sobre a sua qualidade, promovendo a síntese de inibidores. A produção destes compostos é descrita como uma resposta fisiológica da planta a situações estressantes, que podem ser de origem biótica ou abiótica (TAIZ \& ZEIGER, 2004), sendo que a sarcotesta é prejudicial à germinação de sementes de mamão (TOKUHISA et al., 2007b). Em conformidade com estas observações, FREITAS et al. (2011) verificaram efeito benéfico da remoção dessa estrutura sobre a germinação de sementes de $\boldsymbol{J}$. spinosa (Aubli) A. DC.

Nas duas épocas de colheita, verificou-se efeito benéfico da remoção da sarcotesta sobre o vigor avaliado pelo teste de envelhecimento acelerado, sendo mais vigorosas as sementes provenientes do mês de abril (Tabela 2). Em sementes sem a sarcotesta, os maiores valores de plântulas normais na primeira contagem foram obtidos na colheita de outubro. TOKUHISA et al. (2008) detectaram melhor desempenho de sementes colhidas em períodos de 
temperaturas mais elevadas, diferentemente do que foi constatado no presente trabalho, cuja germinação das sementes colhidas em outubro foi inferior às de abril. Estes autores verificaram efeito favorável da remoção da sarcotesta das sementes, independente da época de colheita, o que concorda parcialmente com o que foi observado nas duas épocas de colheita avaliadas neste trabalho, uma vez que, para germinação (Tabela 2) não houve efeito da remoção daquela estrutura para sementes colhidas em abril. Nesta época, a menor concentração de compostos fenólicos na sarcotesta (Figura 1) pode explicar o comportamento semelhante entre sementes com e sem tal estrutura.

Na sarcotesta, há inibidores, principalmente compostos fenólicos, que acarretam germinação lenta e desuniforme das sementes (CHOW \& LIN, 1991), pois os fenóis podem atuar como ativadores ou inibidores do sistema enzimático, de acordo com o tipo e concentração, sendo que seus efeitos podem ser verificados sobre diversos aspectos do crescimento vegetal (COLPAS et al., 2003), pois a concentração de 50ppm de ácido ferúlico inibiu a germinação de sementes de soja.

Pelos resultados da tabela 3, nota-se aumento na germinação e redução da porcentagem de sementes dormentes com o amadurecimento dos frutos. Em espécies de frutos carnosos, como o mamão, o processo de maturação das sementes continua após a colheita. Assim, um período de repouso pós-colheita dos frutos pode permitir que sementes imaturas, ainda presentes no interior destes completem o seu desenvolvimento, resultando em melhor qualidade fisiológica, conforme verificado também em sementes de tomate (DIAS et al., 2006), mamão (AROUCHA et al., 2007) e pimenta (VIDIGAL et al., 2009).

Pela primeira contagem de germinação, observa-se que houve melhor desempenho para sementes de frutos do estádio 5, colhidas em outubro, enquanto, para sementes colhidas em abril, não houve efeito do estádio de maturação do fruto (Tabela 3). A manutenção das sementes no fruto após a colheita contribui para a melhoria da qualidade das sementes, o que estaria associado a alguma alteração entre promotores e inibidores de germinação no interior das sementes (MARTINS et al., 2006). Efeito favorável do armazenamento do fruto sobre a qualidade de sementes também foi observado por AROUCHA et al. (2005) para sementes de mamão 'Golden'. Na colheita de outubro, as sementes tinham menores valores de germinação, enquanto o maior vigor, conforme resultados do teste de envelhecimento acelerado, foi obtido para sementes de frutos colhidos em abril, no estádio final da maturação (Tabela 3). Quanto aos estádios de amadurecimento, em geral, o vigor das sementes de frutos nos estádios de maturação 5 e final foi superior, concordando com o observado por MARTINS et al. (2006) e DIAS et al. (2006), que afirmam que, em espécies com frutos carnosos, o processo de maturação das sementes se estende após a colheita, sendo favorecido por um

Tabela 1 - Porcentagem de germinação, primeira contagem, sementes dormentes pelo teste de tetrazólio e germinação após o envelhecimento acelerado em sementes de mamão com e sem sarcotesta, extraídas de frutos em quatro estádios de maturação nas duas épocas de colheita.

\begin{tabular}{|c|c|c|c|c|}
\hline & Estádio 1 & Estádio 3 & Estádio 5 & Estádio final \\
\hline Sementes & \multicolumn{4}{|c|}{---orminação (\%) CV=17,13\%-- } \\
\hline Com sarcotesta & $26 \mathrm{aC}$ & $31 \mathrm{aBC}$ & $59 \mathrm{bA}$ & $40 \mathrm{bB}$ \\
\hline \multirow[t]{2}{*}{ Sem sarcotesta } & $21 \mathrm{aB}$ & $27 \mathrm{aB}$ & $78 \mathrm{aA}$ & $85 \mathrm{aA}$ \\
\hline & \multicolumn{4}{|c|}{ 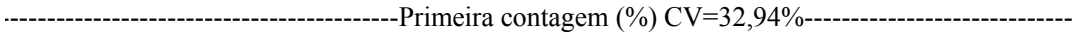 } \\
\hline Com sarcotesta & $0 \mathrm{bB}$ & $2 \mathrm{aB}$ & $16 \mathrm{bA}$ & $5 \mathrm{bB}$ \\
\hline \multirow[t]{2}{*}{ Sem sarcotesta } & $11 \mathrm{aB}$ & $4 \mathrm{aC}$ & $33 \mathrm{aA}$ & $37 \mathrm{aA}$ \\
\hline & \multicolumn{4}{|c|}{--- } \\
\hline Com sarcotesta & $45 \mathrm{bA}$ & $25 \mathrm{bB}$ & $21 \mathrm{aB}$ & $25 \mathrm{aB}$ \\
\hline \multirow[t]{2}{*}{ Sem sarcotesta } & $77 \mathrm{aA}$ & $58 \mathrm{aB}$ & $18 \mathrm{aC}$ & $11 \mathrm{bC}$ \\
\hline & \multicolumn{4}{|c|}{ 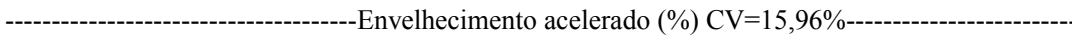 } \\
\hline Com sarcotesta & $8 \mathrm{bC}$ & $11 \mathrm{bC}$ & $20 \mathrm{bB}$ & $39 \mathrm{bA}$ \\
\hline Sem sarcotesta & $24 \mathrm{aD}$ & $42 \mathrm{aC}$ & $73 \mathrm{aA}$ & $62 \mathrm{aB}$ \\
\hline
\end{tabular}

Médias seguidas pela mesma letra, maiúsculas na linha e minúsculas na coluna, não diferem entre si pelo teste de Tukey a $5 \%$ de probabilidade.

Ciência Rural, v.45, n.4, abr, 2015. 
Tabela 2 - Porcentagem de germinação, primeira contagem, sementes dormentes pelo teste de tetrazólio e germinação após o envelhecimento acelerado de sementes de mamão com e sem sarcotesta, extraídas de frutos em duas épocas de colheita.

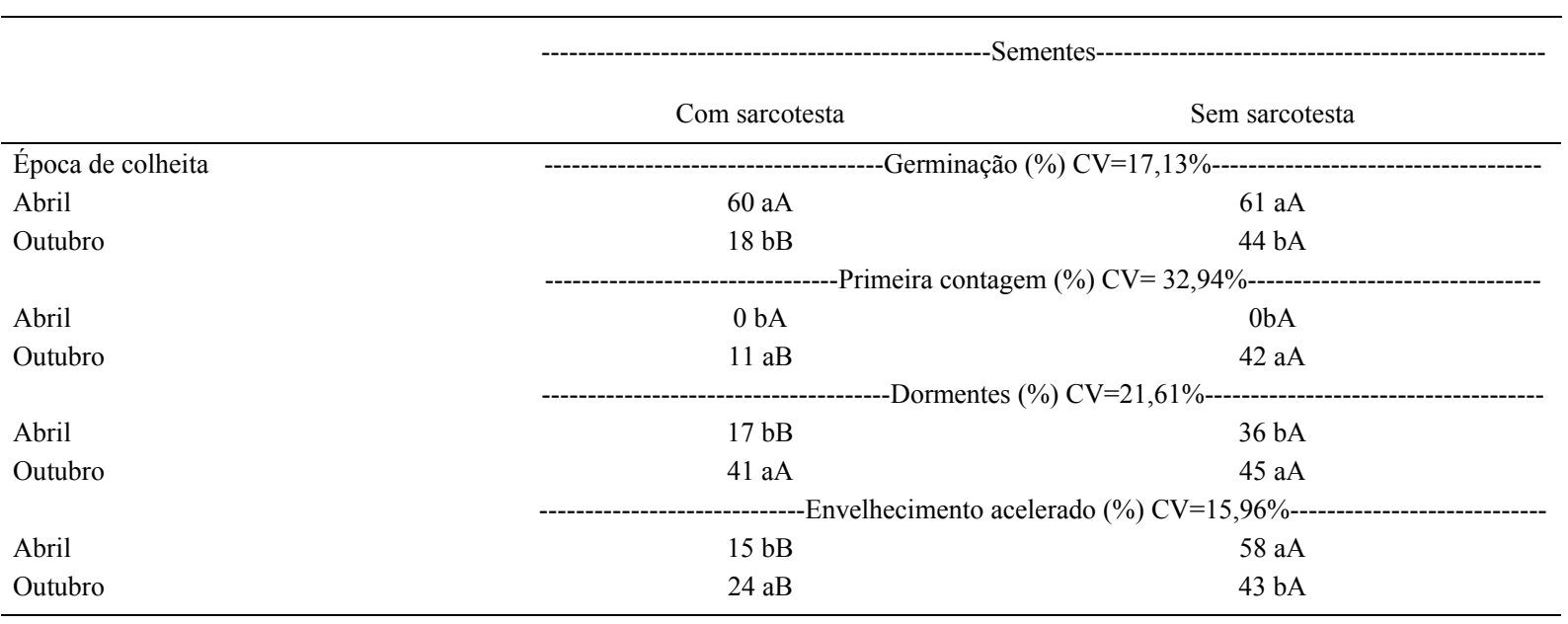

Médias seguidas pela mesma letra, maiúsculas na linha e minúsculas nas colunas, não diferem entre si pelo teste de Tukey a 5\% de probabilidade.

período de repouso pós-colheita dos frutos, no qual o processo se completa.

Pela figura 1, verifica-se maior concentração de compostos fenólicos na sarcotesta em relação às demais estruturas, tanto para frutos colhidos em abril como em outubro, sendo que apenas para a colheita de outubro observa-se maior conteúdo de fenóis na esclerotesta, quando comparada à parte interna da semente. MACIEL et al. (1992) também constataram variação na concentração de fenóis entre as estruturas das sementes de espécies florestais, enquanto TOKUHISA et al. (2007b) verificaram maior concentração de compostos fenólicos na sarcotesta e esclerotesta de sementes de mamão, ocorrendo variação na concentração conforme a época de colheita dos frutos.

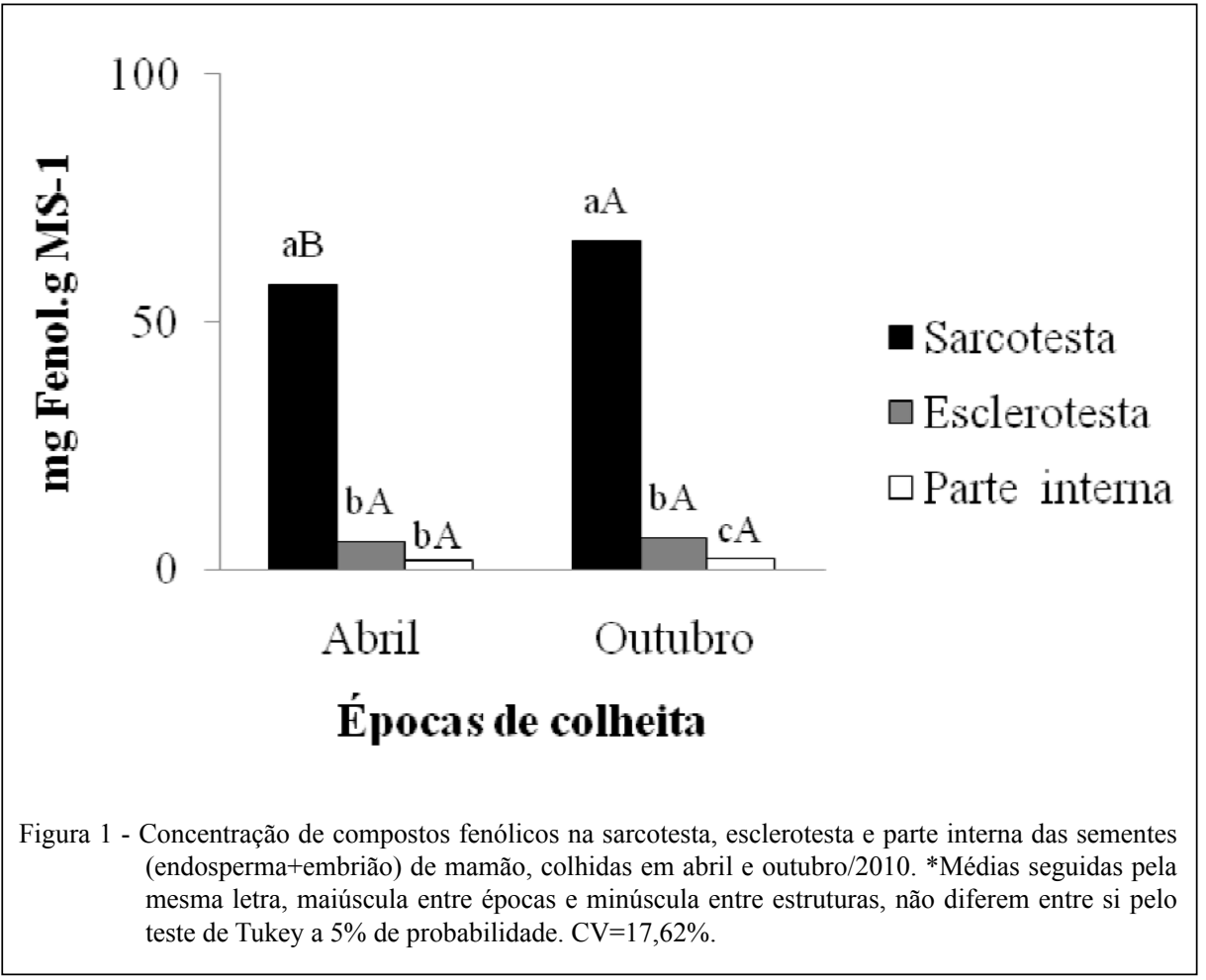

Ciência Rural, v.45, n.4, abr, 2015. 
Tabela 3 - Porcentagens de germinação, primeira contagem, sementes dormentes pelo teste de tetrazólio e envelhecimento acelerado de sementes de mamão extraídas dos frutos em quatro estádios de maturação, nas duas épocas de colheita.

\begin{tabular}{|c|c|c|c|c|}
\hline \multirow{2}{*}{ Época de colheita } & \multirow[b]{2}{*}{ Estádio 1} & \multirow[b]{2}{*}{ Estádio 3} & \multirow[b]{2}{*}{ Estádio 5} & \multirow[b]{2}{*}{ Estádio final } \\
\hline & & & & \\
\hline & -.----. & -------- & $\mathrm{CV}=17,13^{\circ}$ & -------- \\
\hline Abril & $35 \mathrm{aC}$ & $50 \mathrm{aB}$ & $83 \mathrm{aA}$ & $75 \mathrm{aA}$ \\
\hline \multirow[t]{2}{*}{ Outubro } & $13 \mathrm{bB}$ & $8 \mathrm{bB}$ & $54 \mathrm{bA}$ & $50 \mathrm{bA}$ \\
\hline & $0 \mathrm{bA}$ & $0 \mathrm{bA}$ & $\begin{array}{l}\text { \%) } \mathrm{CV}=32 \text {, } \\
1 \mathrm{bA}\end{array}$ & $0 \mathrm{bA}$ \\
\hline \multirow[t]{2}{*}{ Outubro } & $11 \mathrm{aC}$ & $6 \mathrm{aC}$ & $48 \mathrm{aA}$ & $41 \mathrm{aB}$ \\
\hline & & . & $\mathrm{CV}=21,61^{\circ}$ & 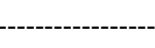 \\
\hline Abril & $60 \mathrm{aA}$ & $37 \mathrm{bB}$ & $6 \mathrm{bC}$ & $3 \mathrm{bC}$ \\
\hline \multirow[t]{2}{*}{ Outubro } & $62 \mathrm{aA}$ & $46 \mathrm{aB}$ & $33 \mathrm{aC}$ & $32 \mathrm{aC}$ \\
\hline & & ----Envelh & ado (\%) CV & \\
\hline Abril & $14 \mathrm{aC}$ & $21 \mathrm{bC}$ & $49 \mathrm{aB}$ & $63 \mathrm{aA}$ \\
\hline Outubro & $19 \mathrm{aC}$ & $33 \mathrm{aB}$ & $44 \mathrm{aA}$ & $38 \mathrm{bAB}$ \\
\hline
\end{tabular}

Médias seguidas pela mesma letra, maiúscula na linha e minúsculas na coluna, não diferem entre si pelo teste de Tukey a $5 \%$ de probabilidade.

Ao se comparar as épocas de colheita, observa-se maior concentração destes compostos na sarcotesta das sementes de frutos colhidos em outubro em relação aos de abril. Assim, é importante notar que, em outubro, os valores de germinação de sementes com sarcotesta (18\%) foram inferiores aos das sementes sem esta estrutura (44\%) (Figura 1), evidenciando que tais compostos provavelmente interferiram na germinação. Esses resultados confirmam os dados obtidos por TOKUHISA et al. (2007b), ao constatarem que a época de maior concentração de fenóis totais nas sementes de mamão coincidiu com a maior ocorrência de dormência nas sementes.

A variação nas condições climáticas em cada época de formação dos frutos pode ter contribuído para a alteração na síntese de compostos fenólicos nas sementes, uma vez que o estresse, seja de origem biótica ou abiótica, é um dos principais fatores responsáveis pela alteração na síntese de compostos secundários em plantas, os quais estão relacionados ao mecanismo de defesa vegetal (RIVERO et al., 2001).

\section{CONCLUSÃO}

As sementes sem sarcotesta, extraídas de frutos nos estádios 5 e final da maturação, são de melhor qualidade fisiológica. A maior concentração de fenóis totais ocorre na sarcotesta e esclerotesta de sementes extraídas de frutos colhidos em outubro, além de também haver maior porcentagem de dormência nessas sementes.

\section{AGRADECIMENTOS}

Ao O Conselho Nacional de Desenvolvimento Científico e Tecnológico (CNPq) pela concessão da bolsa.

\section{REFERÊNCIAS}

ALMEIDA, G.V.B.A. Economia do mamão: o mamão no mundo, no Brasil e na CEAGESP (2007). Toda fruta. Disponível em: <http://www.todafruta.com.br>. Acesso: 12 dez. 2011.

AROUCHA, E.M.M. et al. Época de colheita e período de repouso dos frutos de mamão (Carica papaya L.) cv. Golden na qualidade fisiológica das sementes. Ciência Rural, v.35, n.3, p.537-543, 2005. Disponível em: <http://www.scielo.br/scielo.php?pid=S0103$84782005000300008 \&$ script $=$ sci_arttext $>$. Acesso em: 20 jun. 2011. doi:10.1590/S0103-84782005000300008.

AROUCHA, E.M.M. et al. Qualidade fisiológica de sementes de mamão após armazenamento dos frutos e de sementes. Revista Caatinga, v.20, n.3, p.136-143, 2007. Disponível em: <http:// periodicos.ufersa.edu.br/revistas/index.php/sistema/article/ view/474/192>. Acesso em: 12 out. 2012.

BRASIL. Ministério da Agricultura, Pecuária e Abastecimento. Regras para análise de sementes. Secretaria de Defesa Agropecuária. Brasília: MAPA/ACS, 2009. 395p.

CHOW, Y.J.; LIN, C.H. p-Hydroxibenzoic acid the major phenolic germination inhibitor of papaya seed. Seed Science and Technology, v.19, n.1, p167-174, 1991. 
COLPAS, F.T. et al. Effects of some phenolic compounds on soybean seed germination and on seed-borne Fungi. Brazilian Archives of Biology and Technology, v.46, n.2, p.155-161, 2003.

DELWICHE, L.D.; SLAUGHTER, S.J. The little SAS book: a primer. Cary: SAS Institute, 2003. 268p.

DIAS, D.C.F.S. et al. Tomato seed quality in relation to fruit maturation and post-harvest storage. Seed Science and Technology, v.34, n.3, p.691-699, 2006.

FAO (FOOD AND AGRICULTURE ORGANIZATION). 2009. Disponível em: <http://faostat.fao.org>. Acesso em: 10 mar. 2011.

FREITAS, S.J. et al. Métodos de remoção da sarcotesta na germinação de sementes de jaracatiá. Revista Árvore, v.35, n.1, p.91-96, 2011. Disponível em: <http://www.scielo.br/scielo. php?pid $=$ S0100-67622011000100011\&script $=$ sci_arttext $>$. Acesso em: 10 out. 2011. doi:10.1590/S0100-67622011000100011.

INCAPER (INSTITUTO CAPIXABA DE PESQUISA, ASSISTÊNCIA TÉCNICA E EXTENSÃO RURAL). Boletim Agroclimático. Disponível em: <http:/hidrometeorologia. incaper.es.gov.br>. Acesso em: mar. 2011.

LOPES, A.W.P. et al. Estádio de maturação do fruto e uso de ácido giberélico na germinação de sementes de mamoeiro. Pesquisa Agropecuária Tropical, v.39, n.4, p.278-284, 2009. Disponível em: <http://www.revistas.ufg.br/index.php/pat/article/ view/5763/5572>. Acesso em: 17 abr. 2011.

MACIEL, A.S. et al. Determinação da presença de fenóis em sementes de espécies florestais e sua relação com inibidores de germinação. Revista Brasileira de Sementes, v.14, n.1, p.18, 1992. Disponível em: <http://www.abrates.org.br/revista/ artigos/1992/v14n1/artigo01.pdf>. Acesso em: 30 mar. 2013.

MARTINS, G.N. et al. Superação da dormência em sementes de mamão. In: PAPAYA BRASIL, 2005, Vitória, ES. Anais... Vitória: Instituto Capixaba de Pesquisa, Assistência Técnica e Extensão Rural, 2007. p.241-242. Disponível em: $<$ http://www.fundagres. org.br/downloads/pi-mamao/2005_sementes_mudas_01.pdf $>$. Acesso em: 24 jul. 2014.
MARTINS, G.N. et al. Influência do repouso pós-colheita de frutos na qualidade fisiológica de sementes de mamão. Revista Brasileira de Sementes, v.28, n.2, p.142-146, 2006. Disponível em: <http://www.scielo.br/scielo.php?pid=S010131222006000200019\&script=sci_arttext $>$. Acesso em: $10 \mathrm{dez}$. 2010. doi: 10.1590/S0101-31222006000200019.

RIVERO, R.M. et al. Resistance to cold and heat stress: accumulation of phenolic compounds in tomato and watermelon plants. Plant Science, v.160, n.2, p.315-321, 2001. Disponível em: <http://hera. ugr.es/doi/15090656.pdf>. Acesso em: 09 abr. 2011.

SWAINT, T.; HILLIS, W.E. The phenolic constituents of Prumus domestica. I. The quantitative analyses of phenolic constituents. Journal Science Agricultural, v.10, n.1, p.63-68, 1959.

TAIZ, L.; ZEIGER, E. Fisiologia vegetal. Porto Alegre: Artmed, 2004. 719p.

TOKUHISA, D. et al. Tratamentos para superação da dormência em sementes de mamão. Revista Brasileira de Sementes, v.29, n.1, p.131-139, 2007a. Disponível em: <http://www.scielo. br/scielo.php?pid $=$ S0101-31222007000100018\&script $=$ sci arttext $>$. Acesso em: 01 dez. 2010. doi: 10.1590/S010131222007000100018 .

TOKUHISA, D. et al. Compostos fenólicos inibidores da germinação em sementes de mamão (Carica papaya L.). Revista Brasileira de Sementes, v.29, n.3, p.180-188, 2007b. Disponível em: <http://www.scielo.br/scielo.php?pid=S010131222007000300022\&script $=$ sci_arttext $>$. Acesso em: $11 \mathrm{dez}$. 2010. doi: 10.1590/S0101-31222007000300022.

TOKUHISA, D. et al. Época de colheita dos frutos e ocorrência de dormência em sementes de mamão (Carica papaya L.). Revista Brasileira de Sementes, v.30, n.2, p.75-80, 2008. Disponível em: <http://www.scielo.br/scielo.php?pid=S010131222008000200010\&script $=$ sci_arttext $>$. Acesso em: 20 mar. 2010. doi:10.1590/S0101-31222008000200010.

VIDIGAL, D.S. et al. Sweet pepper seed quality and lea-protein activity in relation to fruit maturation and post-harvest storage. Seed Science and Technology, v.37, n.1, p.192-201, 2009. 